Artigo de Revisão

\title{
Análise do jogo de handebol como ferramenta para sua compreensão técnico-tática
}

\author{
Rafael Pombo Menezes \\ Heloisa Helena Baldy dos Reis \\ Grupo de Estudos e Pesquisas de Handebol, Faculdade de Educação Física, UNICAMP, \\ Campinas, SP, Brasil
}

\begin{abstract}
Resumo: O objetivo deste trabalho é discutir a aplicação de modelos de análise de jogo no handebol, a partir de uma revisão dos modelos e suas possíveis conjecturas com os treinamentos das equipes. Para isso, foram consultados modelos de análise dos componentes técnicos do jogo, assim como referências relacionadas ao comportamento tático dos jogadores. Verificou-se a necessidade da aquisição de parâmetros em situações competitivas, que retratem o comportamento dos jogadores nas suas modalidades, como o desenvolvimento de ferramentas que proporcionem a reprodução e a análise fidedignas das situações de jogo. A análise de jogo tende a aproximar as situações de treino ao jogo, para que os treinamentos apresentem o máximo de especificidade e de transferência para as situações competitivas. A análise de jogo tem papel fundamental nas diversas possibilidades dos treinamentos (técnico-tático, físico entre outras) e deve ser considerada uma ferramenta no treinamento na atualidade.
\end{abstract}

Palavras-chave: Análise de Jogo. Handebol. Jogos Coletivos. Pedagogia do Esporte. Treinamento Desportivo.

\section{Handball match analysis as a tool for technical-tactical comprehension}

\begin{abstract}
The aim of this work is to discuss the application of match analysis models in the handball context, starting from a models revision and their possibilities into teams trainings. For that, models of analysis of the technical components of the game were consulted, as well as references related to the players' tactical behavior. The need of parameters acquisition was verified in competitive situations that represent the players' behavior in their sports, as the tools development that provide a true analysis of the game situations. The game analysis tends to approximate the training situations to the game, to reach the maximum of specificity and transference to the competitive situations. The match analysis is very important in different training possibilities (as a technical-tactical, strength and others) and can be considered as an important tool in modern training.
\end{abstract}

Key Words: Match Analysis. Handball. Collective Sports. Sports Pedagogy. Training Sports.

\section{Introdução}

A busca dos treinadores, jogadores e demais membros de uma comissão técnica pela excelência esportiva, chegou ao ponto de uma partida ser definida por detalhes estratégicotáticos, e uma competição ou um recorde serem vencidos ou perdidos por milésimos de segundo ou milímetros de distância. Alguns detalhes em competições dessa importância passariam despercebidos se não fossem as análises realizadas por laboratórios de pesquisas, que adotam metodologias minuciosas de investigação esportiva, ou por treinadores experts da modalidade. Hughes \& Franks (1997) afirmam que, tradicionalmente, as intervenções dos treinadores em suas modalidades são baseadas em observações subjetivas dos jogadores.

Porém, muitas vezes essas avaliações subjetivas estão predispostas a erros por parte dos treinadores, tanto na questão da análise de movimentos isolados (como nas modalidades individuais) como na análise das interações entre os jogadores de uma mesma equipe ou adversários nos Jogos Coletivos Esportivizados (JCE's - REIS, 1994). Assim sendo, nas modalidades individuais a preocupação na obtenção de resultados, muitas vezes, está associada à busca pela perfeição das técnicas de movimentos do jogador (como a correta execução de uma determinada cadeia de movimentos na ginástica artística, no lançamento do martelo ou na natação).

Nas análises dos JCE's, em especial o handebol, que é o foco deste trabalho, o caráter individual apresenta uma importância diferenciada se comparado com as modalidades individuais. Porém nota-se uma grande influência, nas ações individualizadas e nos resultados das partidas, da interação entre os jogadores de uma mesma 
equipe e das suas relações com seus adversários (em um contexto técnico-tático), as quais não estão submetidas a quaisquer padrões de movimentos ou movimentações préestabelecidas, podendo a "lógica" do jogo ser alterada a qualquer instante e por qualquer protagonista. Nos JCE's nem sempre a forma de execução (ou o como fazer) de uma determinada habilidade está relacionada com a eficácia, mas sim o motivo, o momento e o local precisos de sua execução dentro do contexto do jogo (ou o porquê fazer, o quando fazer e o onde fazer, respectivamente) (GARGANTA, 1995).

O handebol, também é dotado dessa complexidade inerente aos JCE's, baseia-se na interação entre os jogadores que é determinada por estruturas fixas (OLIVER CORONADO \& SOSA GONZÁLEZ, 1996), como as dimensões da quadra, a bola, a duração da partida e o regulamento, e estruturas variáveis, como o número de jogadores, os sistemas de jogo e as formas de execução dos gestos técnicos, sendo uma modalidade com uma grande gama de variáveis a serem quantificadas e analisadas. Quiñonero et al. (2002, p.341), afirmam que "em todo esporte onde se pretendam as máximas excelências esportivas, se requerem mecanismos de avaliação do estado do desportista em seus diferentes âmbitos provocando que sejam numerosas as variáveis a controlar". Essa afirmação nos chama a atenção para um ponto importante sobre a complexidade da análise de uma partida de handebol, principalmente ao envolver variáveis técnico-táticas.

A associação de um modelo de análise de jogo às sessões de treinamento pode ser considerada uma ferramenta para o desenvolvimento dos jogadores na modalidade tanto dos iniciantes como de alto nível de rendimento, uma vez que são considerados parâmetros e valores apresentados em situações da própria competição e com todos os fatores que a permeiam. Segundo Greco (2001, p.51) "o treinamento se apóia no ensino-aprendizagem e, através do seu planejamento consciente e variado, permite a sua fixação e possibilita o crescimento do nível de aptidão". Ou seja, quanto mais o planejamento dos treinamentos se aproximar das quantificações das variáveis e de suas alterações nas situações competitivas, mais eficaz e individualizado será o desenvolvimento dessas aptidões.
É notado um crescente interesse em pesquisa no handebol, na busca de melhor compreensão dos fatores relacionados com o rendimento dos jogadores (PRUDENTE et al., 2004), sendo que um meio de observar os fatores relacionados à performance é pela análise de jogo. Hughes \& Bartlett (2002, p. 739) definem como indicadores de performance a "seleção, ou combinação, de variáveis de ação que objetivam definir alguns ou todos os aspectos da performance".

O objetivo deste trabalho é discutir a aplicação de modelos de análise de jogo no handebol, a partir de uma revisão dos modelos e suas possíveis conjecturas com os treinamentos das equipes.

\section{A análise de jogo e os jogos coletivos esportivizados}

A análise de jogo tem sido aplicada, historicamente, para a investigação não apenas dos movimentos e comportamentos individuais dos jogadores, mas também para investigar as interações entre esses jogadores. Tais estudos acerca das variáveis dos jogadores contribuem para uma melhor compreensão acerca dos parâmetros fisiológicos, técnicos, táticos, psicológicos entre outros das modalidades (HUGHES \& BARTLETT, 2002; PRUDENTE et al., 2004; SANTOS, 2004; MENEZES, 2007).

Hughes \& Bartlett (2002) reportam sobre a utilização da análise de jogo em conjunto com as análises de vídeos, como ferramentas que visam aumentar a performance esportiva, seja ela nos esportes coletivos ou nos individuais. Essas análises, segundo os autores, podem ser utilizadas comparativamente entre os jogadores de uma mesma equipe, entre oponentes ou entre equipes. A partir dos resultados fornecidos por esse tipo de rotina podem ser identificados parâmetros de referência (positiva ou negativa) de rendimento de seus jogadores (individualmente) ou de conjuntos de jogadores (tática grupal e coletiva). Prudente et al. (2004, p. 50) entendem a análise de jogo como um "estudo do jogo a partir da observação da atividade dos jogadores e das equipes".

Quando nos voltamos para uma modalidade coletiva sob um "olhar tático", as combinações e movimentações simultâneas de todos os jogadores na quadra são praticamente indefinidas (em seu número e em suas probabilidades), o que é denominado por Hughes \& Bartlett (2002) de 
habilidades abertas. Para tanto, a análise de jogo nos JCE's busca quantificar indicadores que possam explicar as performances individuais e coletivas, sendo de natureza técnica (relacionados à execução e efetividade dos fundamentos, como os passes e os arremessos no handebol), tática (referentes às interações entre os jogadores e suas movimentações), da preparação física (relacionados com os parâmetros de capacidade física) ou da preparação psicológica.

Segundo Garganta (2001), a análise da performance nos JCE's possibilita: a) identificar integrações entre jogadores e equipes e modelálas; b) identificar atividades que se correlacionam com a obtenção de resultados positivos; c) manipular e recriar constantemente os processos de treinamento para que estes sejam mais específicos; e d) apontar possíveis evoluções esportivas em cada modalidade.

Devido às complexidades de cunhos interacional, cognitivo e coordenativo inerentes aos JCE's, os jogadores devem desenvolver, de forma encadeada e inteligente, seqüências de ações a partir de uma leitura de jogo precisa que gerem tomadas de decisões apropriadas e eficazes para tal contexto. Entendemos, então, que os JCE's estejam diretamente relacionados com a resolução de situações-problema aos quais os jogadores estão submetidos e devem atuar constantemente de forma flexível (GRECO, 2001), e suas ações são tomadas com base na percepção que possuem do jogo, nas ferramentas psicomotoras que possuem para a resolução de uma tarefa, no processamento das informações contidas no jogo e em vivências anteriores na modalidade. Os jogadores são, portanto, interventores diretos dos processos, meios e sistemas do jogo, o que torna de grande relevância que esses apresentem respostas coerentes às diversas situações de jogo, agindo inteligentemente dentro das táticas adotadas para solucionar tais situações.

A tomada de decisão deve respeitar os objetivos específicos de cada fase do jogo na qual a equipe se encontra e o contexto tático naquele instante, sendo que no handebol são caracterizadas três fases com objetivos inerentes à cada uma: ofensiva, defensiva (BAYER, 1994) e transições. O domínio das técnicas específicas dessas fases e a capacidade de tomada de decisão do jogador dependem da sua adequabilidade à situação de jogo (GARGANTA \& OLIVEIRA, 1996). Na figura 1 está representado um diagrama com os objetivos específicos de cada fase no jogo, bem como suas possíveis interações, baseado nos princípios operacionais (adaptado de BAYER, 1994).

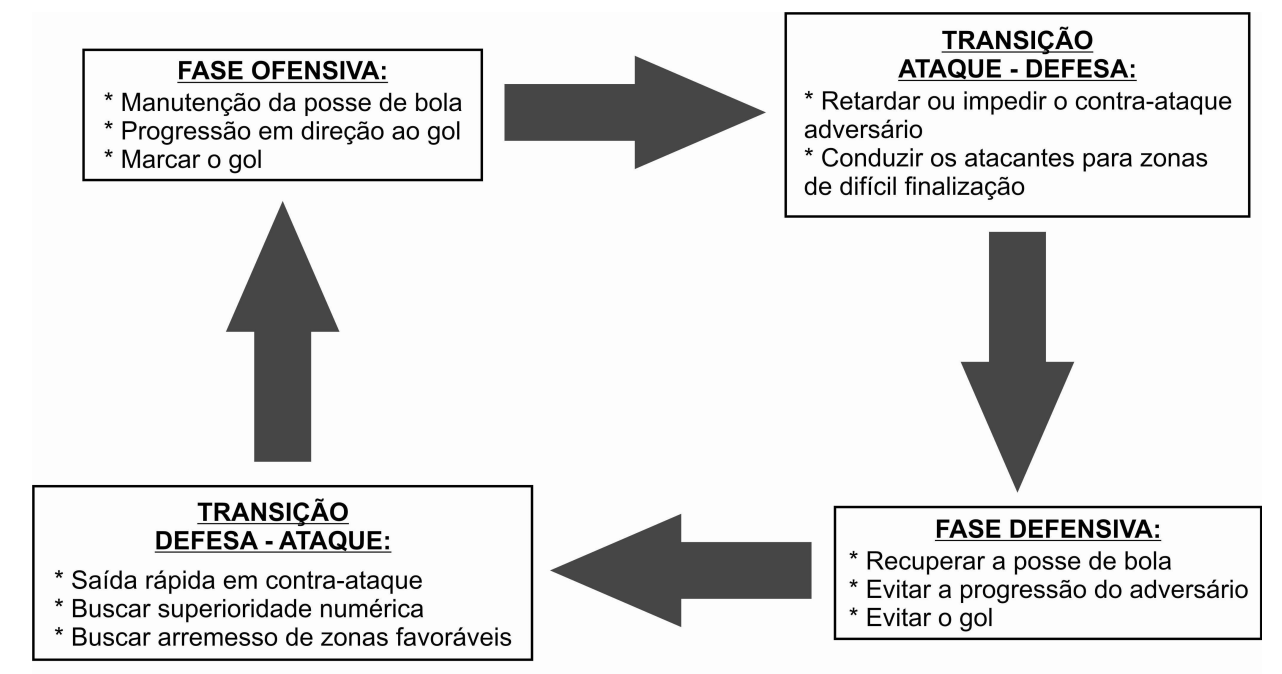

Figura 1. Diagrama representativo das fases de jogo e seus respectivos norteadores.

Para cada uma dessas fases há as escolhas de sistemas de jogo específicos, que irão nortear o posicionamento e o comportamento tático de todos os jogadores. O sistema de jogo é a forma na qual os jogadores se distribuem na quadra durante 0 jogo, sendo uma estrutura indispensável da tática coletiva ofensiva e defensiva (MOREIRA \& TAVARES, 2004).

Os sistemas de jogo são treinados em uma equipe de handebol e adaptados, na maioria dos casos, com base em alguns fatores, como: a) as características dos jogadores que a compõem 
(considerando variáveis como as antropométricas, a velocidade, a força e as capacidades de percepção e antecipação das situações de jogo); e b) as características dos adversários (considerando os sistemas adotados por esses e as características de seus jogadores).

Com a complexidade de fatores impostos pelas situações-problemas dos JCE's, e a influência direta da estratégia e da tática adotadas pelas equipes (nas fases de ataque, defesa $e$ transições) e pelas características de cada jogador, pesquisadores desenvolvem metodologias para quantificar e analisar modalidades esportivas que são dirigidas para diferentes enfoques (puramente técnico, como o desenvolvido pela EHF que será descrito posteriormente; técnico-tático, como o desenvolvido por SANTOS, 2004; ou da preparação física, como o desenvolvido por GRECO, 2000).

Assim sendo, há a necessidade da aquisição de parâmetros em situações competitivas, que retratem o comportamento dos jogadores dentro de suas modalidades, como o desenvolvimento de ferramentas que proporcionem a reprodução e a análise fidedignas das situações de jogo. Se uma análise fornece valores adulterados ou deturpados das situações do jogo ou que não quantifiquem adequadamente as variáveis selecionadas, há um comprometimento da interpretação desses dados, que poderá provocar equívocos na construção dos sistemas e na análise do jogo.

O surgimento dos métodos de análise de jogo era baseado especificamente na aquisição e análise de dados realizados manualmente, por pesquisadores interessados, principalmente, no estudo do aproveitamento técnico no futebol. Ohashi et al. (1987), a partir da utilização de duas câmeras de vídeo, desenvolveram um método para registrar as velocidades e distâncias percorridas por um jogador durante uma partida de futebol. Já Partridge et al. (1993), com enfoque na performance técnica, desenvolveram um sistema composto por um painel digitalizador adaptado a um computador para analisar a Copa do Mundo de 1990. Erdmann (1993) realizou um estudo cinemático do posicionamento de jogadores de futebol a partir da adaptação de uma folha quadriculada à tela da televisão, na qual eram transcritos os pontos correspondentes ao jogador na tela durante a reprodução quadro a quadro a fim de representar suas trajetórias.

Apesar de as metodologias anteriormente citadas abordarem diferentes enfoques (tático e, principalmente, técnico), essas possuem em comum 0 fato de serem extremamente trabalhosas (pois quanto mais variáveis se queira quantificar maior deverá ser o número de pessoas envolvidas) e terem um custo alto quando nos referimos ao tempo gasto para a quantificação e a análise dos dados, principalmente pelo fato de não terem os computadores como meios dessas finalidades.

Mais recentemente houve a incorporação, nos procedimentos de quantificação, arquivamento, processamento e análise dos dados, de outros mecanismos decorrentes de inovações tecnológicas, tais como computadores, notebooks e palmtops, que permitem arquivar mais dados e, conseqüentemente, proporcionar a análise de um número maior de variáveis com o envolvimento de um número menor de pessoas nessas etapas.

Ainda no âmbito do futebol, que tem sido o esporte com o maior número de metodologias propostas para análises, talvez por fatores como sua popularidade, sua espetacularização e seu mercado consumidor internacional, Hennig \& Briehle (2000) desenvolveram um método de rastreamento dos jogadores por GPS (Global Positioning System - utilizado para navegação e por pilotos de rally), para registrar a distância e a velocidade dos deslocamentos desses. Papadimitriou et al. (2001) compararam estatisticamente, a partir da filmagem dos jogos das quatro equipes semi-finalistas da Copa do Mundo de 1998 e da utilização de computadores para armazenamento dos dados, as ações defensivas dessas equipes. Figueroa et al. (2006) desenvolveram um método de rastreamento automático dos jogadores que permite 0 arquivamento das posições dos jogadores (de ambas as equipes) em função do tempo, possibilitando as análises das trajetórias, a quantificação das distâncias percorridas e as velocidades desses durante a partida.

Valadés et al. (2002) descrevem a importância, neste caso aplicado ao voleibol, de analisar os adversários previamente em conjunto com a equipe durante as sessões de treinamento para conhecer $e$ assimilar os pontos fracos $e$ estratégias desses, e treinar para buscar soluções 
táticas individuais e coletivas para as fases do jogo (defensiva, ofensiva e de contra-ataque).

Oslin et al. (1998) desenvolveram um modelo de análise dos JCE's denominado de GPAI (da tradução: Instrumento de Avaliação do Desempenho no Jogo), cujo objetivo é avaliar as habilidades básicas e as competências relacionadas com o jogo. Os autores identificaram sete componentes do jogo, também relacionados com os princípios operacionais (BAYER, 1994), os quais podem ser utilizados para as análises de componentes individuais como também do envolvimento e performance no jogo em um panorama global.

Os modelos de análise de jogo do handebol reportados na literatura, quando comparados com esportes como o futebol, ainda apresentam-se em escassez em seu número. Um dos principais problemas quanto às produções existentes (exceto dissertações de mestrado e teses de doutorado) é, quanto aos aspectos metodológicos, "a falta de rigor e clareza", além dos "métodos de aquisição e análise dos dados" (SANTOS, 2004, p. 6).

Em análise do handebol, temos como referência o método proposto por Pers \& Kovacic (2000) que, a partir das imagens capturadas por duas câmeras, analisaram uma partida experimental de handebol, na qual foram quantificadas as distâncias percorridas e velocidades dos jogadores. Menezes (2007), também a partir das imagens de duas câmeras, propôs e avaliou um método de análise cinemática de jogadores de handebol capaz de quantificar, com precisão, variáveis como trajetórias de todos os jogadores, suas distâncias percorridas e velocidades, que estão diretamente relacionadas ao comportamento tático e à preparação física.

Oliver Coronado (2005) desenvolve um trabalho, com as equipes femininas participantes das Olimpíadas de 2004, objetivando: a) estudar os diferentes dados estatísticos de cada equipe (como altura, peso, valores antropométricos e idade das jogadores, além dos arremessos realizados de cada posição, gols marcados, a participação de cada jogadora no tempo total de jogo); e b) avaliar qualitativamente a competição e cada equipe nacional (a partir da observação dos jogos e dos dados quantitativos).
A EHF (European Handball Federation) realiza após cada competição uma análise quantitativa das equipes envolvidas. Essa análise contém informações referentes ao aproveitamento dos arremessos de cada jogador em cada região da quadra e do aproveitamento dos goleiros, ambas com dados referentes à técnica individualizada. Greco (2000) descreve alguns procedimentos de avaliação de jogos de handebol, baseados na anotação manual de dados em cinco planilhas, sendo: a) scout de observação (seqüência de jogo); b) scout técnico; c) scout de observação tática; d) observação de gols e atuação do goleiro; e e) scout tático de contra-ataque.

Santos (2004) desenvolveu um estudo que, pela observação e análise de equipes de handebol de alto nível de rendimento (finalistas de Campeonatos Mundiais e Jogos Olímpicos), possibilitou descrever padrões de organização tática dessas equipes a partir de categorias e indicadores de sucesso dos jogadores e suas eficácias nas diferentes condições do jogo.

Essas análises de jogo devem (ou deveriam) ser capazes de identificar o maior número possível de variáveis relevantes nos sistemas adotados para cada uma das etapas do jogo e no seqüenciamento de procedimentos dos jogadores, permitindo que fatores passíveis de imprevisibilidade do jogo sejam corretamente analisados, arquivados e transcritos para as situações do treinamento. Dessa forma seria possível avaliar o panorama tático coletivo das equipes, permitindo a intervenção do treinador no método de ensino de cada equipe, na seleção e ajuste de seus sistemas ofensivos e defensivos, e também na ênfase dada a alguns meios táticos executados isoladamente ao contexto do jogo.

Entendemos que um modelo de análise de jogo deve ter uma estreita relação com os treinamentos da equipe avaliada, tanto em relação à sua gênese quanto à sua aplicação. $A$ gênese da análise de jogo deve ser pautada em fatores como a categoria da equipe a ser analisada (a partir das divisões por idades estipuladas pelo regulamento), no seu nível competitivo (iniciantes, amadores, profissionais...) e, principalmente, na coerência com o trabalho técnico-tático que o treinador desenvolve com seus jogadores. Ou seja, de acordo com a metodologia adotada por um treinador a análise de jogo poderá apresentar uma conotação mais voltada aos parâmetros técnicos ou táticos. $\mathrm{Na}$ 
figura 2 está representado um diagrama sobre as possibilidades e conexões entre as análises técnicas e táticas, bem como o que é esperado para cada tipo de análise.

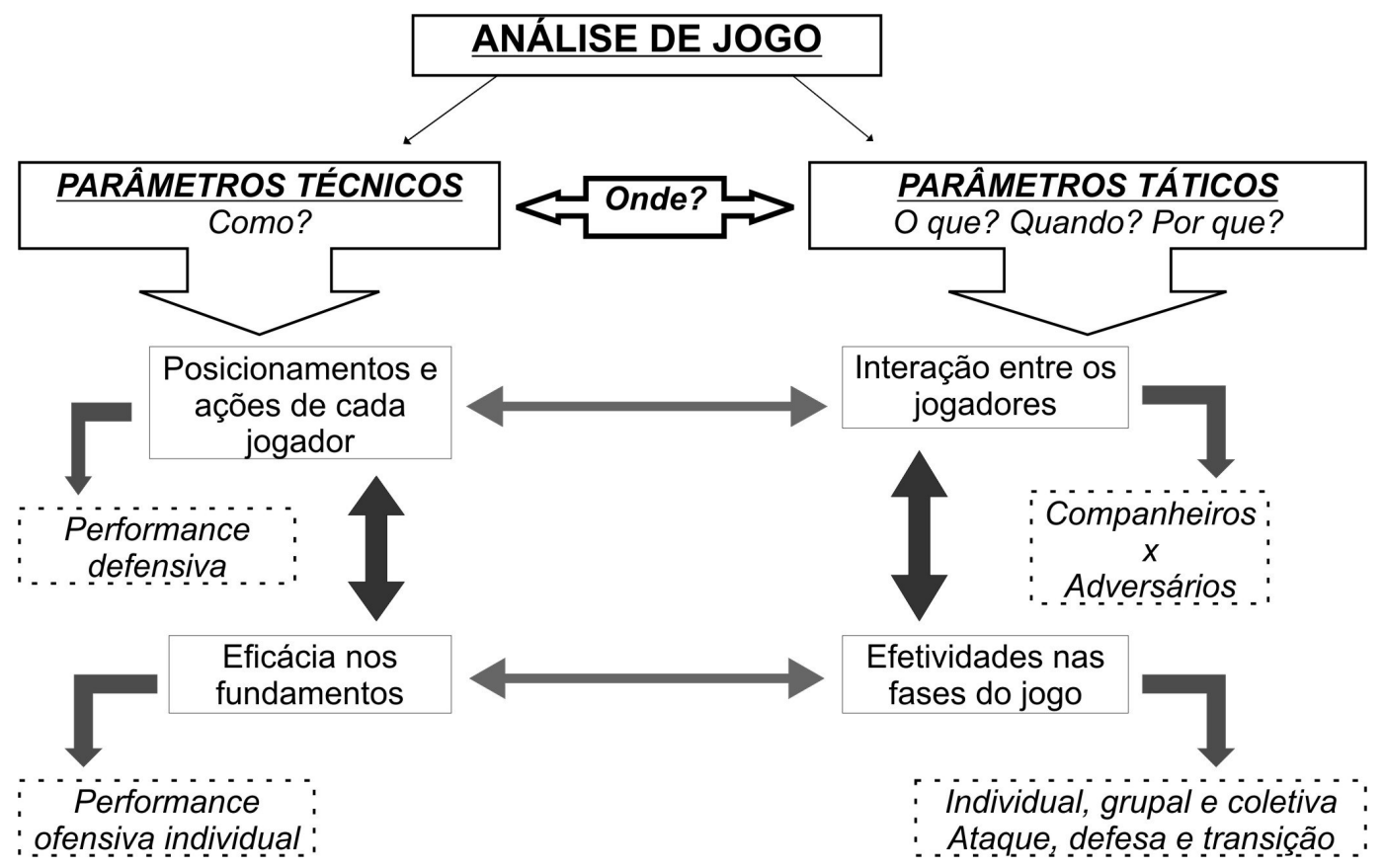

Figura 2. Diagrama de blocos com as possibilidades da análise de jogo e as conexões entre as variáveis técnicas e táticas.

Um modelo de análise de jogo, para ser desenvolvido e aplicado, necessita de um planejamento prévio baseado nas características das equipes a serem analisadas, como a categoria dessas, por exemplo. Até o momento de sua aplicação é preciso definir os parâmetros que serão avaliados (ou as variáveis de interesse), bem como a forma de coletar, armazenar (seja em computadores ou planilhas preenchidas manualmente) e interpretar esses dados (como esses serão apresentados para a comissão técnica). A pré-definição de parâmetros é importante para o balizamento da análise, definindo a natureza das variáveis a serem quantificadas (técnicas, táticas ou capacidades físicas) e seus possíveis desdobramentos durante a análise.

A quantificação desses parâmetros proverá do armazenamento do conjunto de dados coletado durante a realização do jogo, que permitirá avaliar e selecionar os parâmetros mais significativos para que sejam contextualizados com a metodologia de treinamento da equipe. Para que essa intervenção seja mais eficaz, torna-se necessária uma aproximação do modelo de análise de jogo e a metodologia de treinamento da equipe analisada. Contempla-se, dessa forma, as variáveis que a equipe obteve desempenho abaixo do esperado e que, simultaneamente, contemple também as variáveis que a equipe obteve maior êxito. Esse modelo de treinamento deve ser composto por exercícios específicos objetivando um aprendizado mais aprofundado da modalidade, seja para ajustes individuais, grupais ou coletivos.

Essa análise de jogo fornecerá, de forma precisa ou imprecisa, parâmetros relacionados às performances de interesse do treinador ou do preparador físico. Ao final do processo devem ser analisadas, durante as sessões de treinamento, as respostas desses jogadores ao serem submetidos à aprendizagem das variáveis propostas. A quantificação durante um jogo posterior ao treinamento permitirá a reavaliação do jogador em situação competitiva, indicando possíveis alterações na performance.

Paralelamente às sessões de treinamento, deverá ser feita uma análise do modelo utilizado para coletar as variáveis durante o jogo, cabendo ou não alterações de variáveis ou de procedimentos de quantificação dos dados. $\mathrm{Na}$ figura 3 está representado um esquema da sistematização do processo de análise de jogo com as etapas descritas anteriormente. 


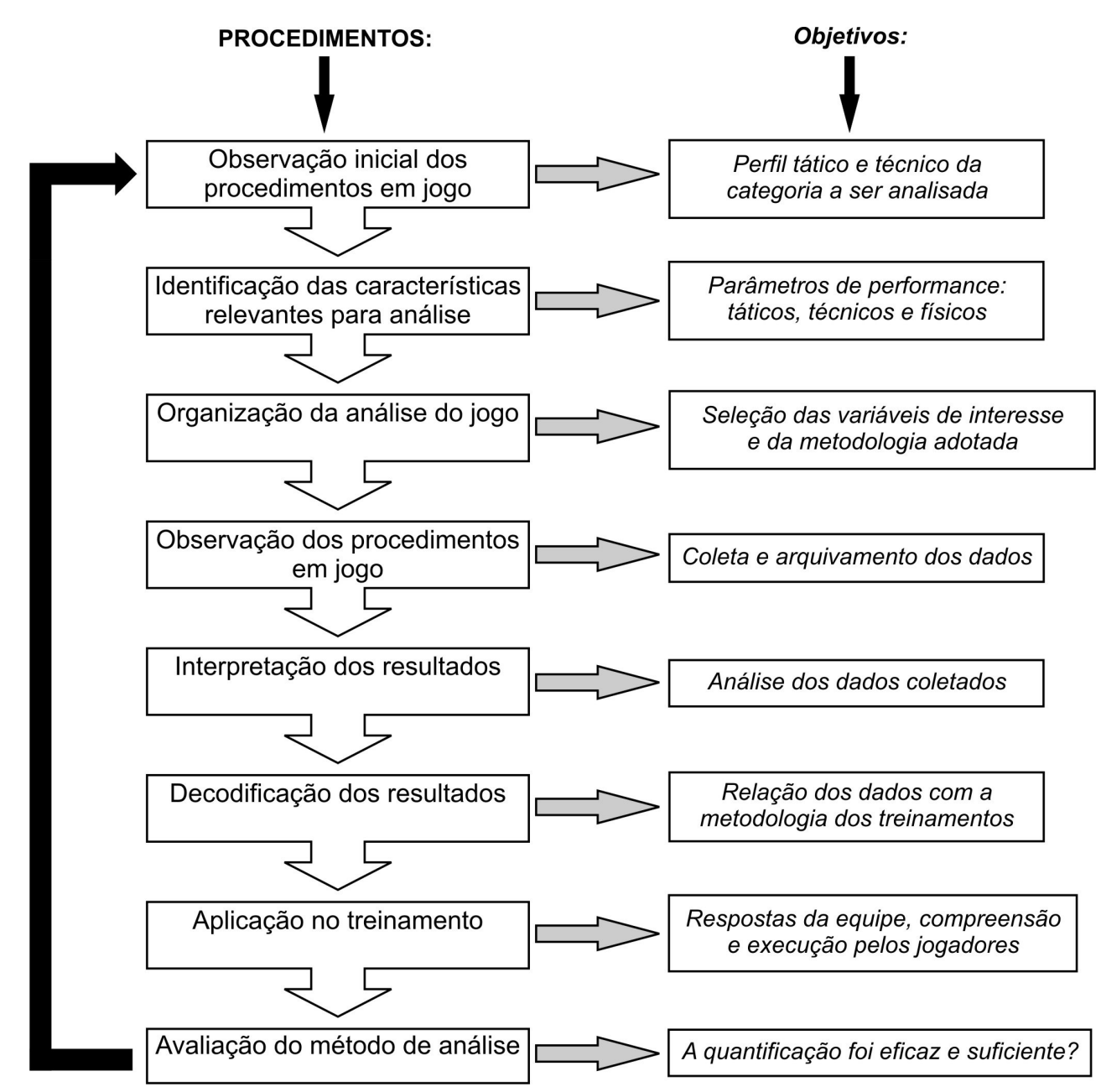

Figura 3. Sistematização do processo de análise de jogo e a sua integração com os treinamentos.

Vale ainda ressaltar que a análise de jogo é um processo de constante retroalimentação, ou seja, após a aplicação dos dados fornecidos por essa no treinamento da equipe é necessária a reavaliação e reaplicação do processo, principalmente em questões referentes às variáveis a serem analisadas e aos procedimentos de coleta e armazenamento dos dados.

\section{Considerações Finais}

O estudo das interações entre os jogadores é, assim como os JCE's, um fenômeno complexo de ser desenvolvido e dependente das características da modalidade em estudo, que apresenta interações entre jogadores intra e inter equipes. Lames \& Hansen (2001) apud Prudente et al. (2004) afirmam que a análise de jogo deve medir as performances dos jogadores, seja individual, das capacidades físicas ou das soluções táticas para determinadas situações.
Lames (2006) afirma que, se os esportes são dotados de processos dinâmicos de interações entre os jogadores, quando olhamos para os métodos de análises temos duas conseqüências: 1) alguns métodos tradicionais para análise da performance na ciência do esporte são duvidosos, pois buscam normas, principalmente de habilidades individuais, que desrespeitam a dinâmica do jogo; 2) essa "dúvida" causada em relação aos métodos tradicionais estimula a busca por novos modelos de análise capazes de descrever as interações e dinâmicas de um jogo. Dessa forma torna-se necessário, assim como descrito anteriormente, o desenvolvimento de modelos que permitam quantificar e avaliar situações referentes à dinâmica do jogo.

Segundo Oslin et al. (1998) os valores dos testes das habilidades motoras não representam a habilidade que o jogador tem para executá-las de forma apropriada ao contexto do jogo. Ou seja, as análises de jogo, se forem aplicadas de forma a buscar um melhor entendimento da modalidade, 
devem levar em consideração variáveis que extrapolem o tradicionalismo técnico pelo qual o handebol é ensinado com base no método analítico, mas com direcionamento para os parâmetros comportamentais e interacionais dos jogadores, para que esses possuam dados sobre suas intervenções táticas.

Devido a grande flexibilidade de variáveis que os JCE's apresentam em diferentes situações competitivas, cada treinador opta, principalmente, por questões de cunho técnico ou técnico-tático. Muitos desses preferem as análises referentes aos fundamentos (análise técnica, ou das habilidades motoras) dos jogadores, como passes, arremessos ou recepções (certos ou errados).

Mas há um grupo de treinadores que preferem analisar alguns meios táticos ofensivos (análise tática), como a incidência de cruzamentos, trocas de postos específicos ou mesmo alterações de sistemas de jogo. Segundo Moreira \& Tavares (2004, p. 31), "a utilização de meios táticos de grupo revela-se como o complemento dos sistemas de jogo, permitindo alguma criatividade a partir de combinações simples de dois ou três jogadores".

A análise da dinâmica do jogo, de grande relevância para o estudo da tática do handebol, deve abordar também os fatores imprevisíveis ocorridos durante a partida. Ou seja, temos uma estrutura de jogo no handebol que é conhecida, organizada e regulamentada, porém os procedimentos adotados pelos jogadores e 0 conteúdo das ações e sistemas são aleatórios, o que dificulta os procedimentos de análise.

Desta forma, quando há a crítica aos modelos de análise de jogo que consideram apenas as ações técnicas dos jogadores e suas respectivas eficácias, significa que a modalidade deve ser entendida de forma mais abrangente do que apenas a soma das partes que a compõem, ou seja, devem ser considerados os momentos e situações de execução de cada procedimento ofensivo, defensivo e de transição. Prudente et al. (2004, p.51) afirmam que "no âmbito esportivo estamos perante uma situação social em mudança permanente, pelo que os procedimentos estáticos de análise não são suficientes, antes requerem uma perspectiva dinâmica das condutas".
As práticas de analisar os jogos e quantificar variáveis que mensurem um determinado tipo de desempenho permitem uma transformação das situações de jogo em formas ou modelos de treinamentos mais eficazes, principalmente quando nos referimos à especificidade no treinamento esportivo (WEINECK, 1999). Especificidade esta que pode ser relacionada com os fatores técnicos, táticos ou das capacidades físicas.

A combinação dos fatores relacionados com a análise do jogo em consonância com as sessões de treinamentos depende diretamente de quatro variáveis: a) das variáveis a serem analisadas; b) do método de quantificação e análise dessas variáveis; c) do entendimento das situações de jogo (percepção); e d) do método adotado pelo treinador na interpretação e aplicação dos resultados.

A prática da análise de jogo tende a aproximar, a cada dia, as situações de jogo aos treinos (e vice-versa) para que os esportes sejam treinados com o máximo de especificidade e com maior possibilidade de transferência das competências treinadas para aquelas apresentadas em competições. Essa prática nos permite afirmar que a análise de jogo tem papel fundamental nos treinamentos táticos e que deva ser vista como uma ferramenta no treinamento na atualidade.

Essa importância citada acerca da análise de jogo não deve ser um campo de estudos relacionado apenas aos aspectos técnico-táticos, mas sim a aqueles que buscam parâmetros para melhor entendimento da dinâmica de jogo, que também abarca temas como as preparações física e psicológica.

\section{Referências}

Bayer C. O ensino dos desportos colectivos. Lisboa: Dinalivros, 1994.

EHF - European Handball Federation. Disponível em: www.eurohandball.com . Acesso em 22 fev. 2008.

Erdmann WS. Quantification of games preliminary kinematic investigations in soccer. In: Science and Football II, published by E \& FN SPON, Great Britain, p.174-179, 1993.

Figueroa PJ, Leite NJ, Barros RML. Tracking soccer players aiming their kinematical motion analysis. Computer Vision and Image Understanding, 2006; 101: 122-135. 
Garganta J. Para uma teoria dos jogos desportivos colectivos. In: Graça A, Oliveira J. (Ed.) O Ensino dos Jogos Desportivos. Porto: Faculdade de Ciências do Desporto e de Educação Física. Porto: Centro de Estudos dos Jogos Desportivos, 1995, 2ª ed., p. 11-25.

Garganta J, Oliveira J. Estratégia e táctica nos jogos desportivos colectivos. In: Oliveira J, Tavares F. (eds). Estratégia e Táctica nos Jogos Desportivos Colectivos. Porto: Centro de Estudos dos Jogos Desportivos, 1996, p. 9-23.

Garganta J. A análise da performance nos jogos desportivos. Revisão acerca da análise do jogo. Revista Portuguesa de Ciências do Desporto. 2001; v. 1, n. 1: 57-64.

Greco PJ. Métodos de ensino-aprendizagemtreinamento nos jogos esportivos coletivos. In: Garcia ES, Lemos KLM. Temas Atuais VI em Educação Física e Esportes. Belo Horizonte: Saúde Ltda., 2001, p.48-72.

Greco PJ (org.). Caderno de rendimento do jogador de handebol. Belo Horizonte: Editora Health, 2000.

Hennig EM, Briehle R. Game analysis by GPS satellite tracking of soccer players. In: XI Congress of the Canadian Society of Biomechanics. Canadá, 2000, p.44.

Hughes MD, Franks IM. Notational Analysis of Sport. Great Britain: E \& FN SPON, 1997.

Hughes MD, Bartlett RM The use of performance indicators in performance analysis. Journal of Sports Sciences, 2002; 20: 739-754.

Lames M. Modelling the interaction in game sports - relative phase and moving correlations. Journal of Sports Science and Medicine. 2006; 5: 556560.

Menezes RP. Análise cinemática das trajetórias de jogadores de handebol obtidas por rastreamento automático. 2007. $131 \mathrm{f}$. Dissertação de Mestrado, Faculdade de Educação Física, Universidade Estadual de Campinas.

Moreira I, Tavares F. Configuração do processo ofensivo no jogo de andebol pela relação cooperação/oposição relativa à zona da bola. Estudo em equipas portuguesas de diferentes níveis competitivos. Revista Portuguesa de Ciências do Desporto. 2004; v. 4, n. 1: 29-38.

Ohashi J, Togari H, Isokawa M, Suzuki S. Measuring movement speeds and distances covered during soccer match-play. I World
Congress of Science and Football, Liverpool, 1987, p.329-333.

Oliver Coronado JF, Sosa González PI. Balonmano: la actividad física y deportiva extraescolar en los centros educativos. Barcelona: Ministerio de Educación y Cultura, 1996.

Oliver Coronado JF. Juegos de la XXVIII Olimpiada: Atenas 2004 - Análisis de la Competición Femenina de Balonmano. Jornadas Internacionales de Balonmano "Veranos de Oro", Málaga, 2005.

Oslin JL, Mitchell SA, Griffin LL. The Game Performance Assessment Instrument (GPAI): development and preliminary validation. Journal of Teaching in Physical Education. 1998; 17 : 231-243.

Papadimitriou K, Taxildaris K, Alexopoulos P, Mavromatis G, Papas M. Defensive actions of finalist soccer teams in 18th World Cup in France. Journal of Human Movement Studies. 2001; 41 : 125-139.

Partridge D, Mosher E, Franks IM. A computer assisted analysis of technical performance - a comparison of the 1990 World Cup and Intercollegiate Soccer. In: Science and Football II, published by E \& FN SPON, Great Britain, 1993, p.221-231.

Pers J, Kovacic S. Computer vision system for tracking players in sports games. In: I International Workshop on Image and Signal Processing and Analysis. Croácia, 2000.

Prudente J, Garganta J, Anguera MT. Desenho e validação de um sistema de observação no andebol. Revista Portuguesa de Ciência do Desporto. 2004; v. 4, n. 3: 49-65.

Quiñonero L, Martin A, Chirosa LJ. Desarrollo de um soporte informático como organizador del control del entrenamiento em deportes colectivos: balonmano. In: Díaz MZ, Ríos IJC, Ríos LJC, Ramirez JV (eds.). Tecnología y metodología científica aplicada al control y evaluación del rendimiento deportivo. 1a edição. Granada: Reprografia Digital Granada, 2002, p. 341-352.

Reis HHB. O ensino dos jogos coletivos esportivizados na escola. 1994. $75 \mathrm{f}$.

Dissertação de Mestrado, Centro de Educação Física e Desporto, Universidade Federal de Santa Maria.

Santos LR. Tendências Evolutivas do Jogo de Andebol. Estudo centrado na análise da performance táctica de equipas finalista em Campeonatos do Mundo e Jogos Olímpicos. 
2004. $181 \mathrm{f}$. Tese de Doutorado, FCDEF, Universidade do Porto, Portugal.

Valadés D, Hernández E, Lozano C, Ureña A. EI control y análisis del oponente antes y durante la competición como base del entrenamiento de prepartido y toma de decisiones durante la competición. In: Díaz MZ, Ríos IJC, Ríos LJC, Ramirez JV (eds.). Tecnología y metodología científica aplicada al control y evaluación del rendimiento deportivo. $1^{\underline{a}}$ edição. Granada:

Reprografia Digital Granada, 2002, p. 223-244.

Weineck J. Treinamento ideal. São Paulo:

Editora Manole, 9ª edição, 1999.

\section{Endereço:}

Rafael Pombo Menezes

Rua das Camélias, 85/304 Jardim das Rosas

Itu SP Brasil

13309-510

Telefone: (11) 9431-2631

e-mail: rafael.pombo@yahoo.com.br helobaldy@yahoo.com

Recebido em: 26 de junho de 2009.

Aceito em: 30 de novembro de 2009.

\section{(9) $\Theta \Theta$}

Motriz. Revista de Educação Física. UNESP, Rio Claro, SP, Brasil - elSSN: 1980-6574 - está licenciada sob 